\title{
Perinatal Consequences of Gestational Hypertensive Disorder
}

\author{
Cuma Tasin \\ Department of Obstetrics and Gynecology, \\ Mersin University, Faculty of Medicine, Mersin, Turkey \\ E-mail: cumatasin@gmail.com
}

\begin{abstract}
Objective: Our aim in this study was to compare the perinatal outcomes of patients with gestational hypertensive disorder in a tertiary health institution of our country. It was aimed to compare the pregnancy outcomes and the relationship of the disease according to the clinical weights of these patients.

Methods: In this study, 451 patients diagnosed with gestational hypertensive disorder and 122 control patients were evaluated retrospectively in Mersin University Obstetrics and Gynecology Clinic between 2010-2018. The patients were subdivided according to their diagnosis as hypertensive. The patients were averaged according to the age birth weeks. Additional disorders related to pregnancy were recorded in patients diagnosed with gestational hypertensive disorder. Multiple pregnancies were not listed, the control group was taken from maid pregnancies over 37 weeks. In the study, all groups were compared with the control group. $\mathrm{P}<0.05$ was accepted as statistically significant

Results: When the demographic characteristics of the patients are examined, it was observed that mothers with chronic hypertension and gestational hypertension were in older ages; eclampsia was observed in younger patients. It was found that patients with severe preeclampsia, eclampsia and hellp, whose disease severity increased, had earlier births and had lower birth weight. When the perinatal results of the patients are compared, just like fetal weight; As disease severity increased, intrauterine growth retardation (IUGR) increased. Only in gestational hypertensive patients, unlike fetal weight, 52\% of patients were diagnosed with IUGR. Likewise, in gestational hypertensive disorder groups where disease severity increased, excessive low birth weight (LBW) fetus and delivery rate below 34 weeks were increased.
\end{abstract}

Conclusions: In our hospital, which is a tertiary health institution, gestational hypertensive disorder insi dance was found to be $6 \%$. In our study, preeclampsia was the most common group in $69 \%$ of gestational hypertensive disorder. It was observed that pregnant women with chronic hypertension were older, and eclamptic pregnant women were younger. As the severity of the disease increased, the rates of comorbidity (such as IUGR) increased and the patients were delivered in earlier weeks. As the severity of the disease increased, the rate of very low birth weight infant increased proportionally due to preterm delivery and IUGR.

Keywords: Gestational hypertensive disorder, Preeclampsia, perinatal outcomes

DOI: $10.7176 / \mathrm{JSTR} / 6-05-01$

\section{Gestasyonel Hipertansif Bozukluğunun Perinatal Sonuçları}

\section{Özet}

Amaç: Bu çalışmadaki amacımız, ülkemizin üçüncü basamak bir sağlık kuruluşun da gestasyonel hipertansif bozukluk olan hastaların perinatal sonuçlarını karşılaştırma amaçlandı. Bu hastaların klinik ağırlıklarına göre gebelik sonuçlarını ve hastalık ilişkisini karşılaştırmak istendi.

Yöntem: Bu çalışmamızda 2010-2018 yılları arasında Mersin Üniversitesi Kadın Hastalıkları ve Doğum Kliniğinde gestasyonel hipertansif bozukluk tanısı alan 451 hasta ve 122 tane de kontrol hastasi retrospektif olarak değerlendirildi. Hastalar hipertansif olarak tanılarına göre alt gruplara ayrıldı. Hastaların yaş doğum haftalarına göre ortalamaları alındı. Gestasyonel hipertansif bozukluk tanısı alan hastalarda gebelik ile ilgili ek rahatsılıklar kaydedildi. Çoğul gebelikler listeye alınmadı, kontrol grubu

1 I $\mathrm{P}$ a g e www.iiste.org 
37 hafta üzerindeki maid gebelerden alındı. Çalışmada tüm gruplar kontrol grubu ile karşılaştırıldı. İstatistiği olarak $\mathrm{p}<0,05$ anlamlı olarak kabul edildi

Bulgular: Hastaların demografik özellikleri incelendiğinde kronik hipertansiyon ve gestasyonel hipertansiyonlu annelerin daha ileri yaşlarda eklemapsinin ise daha genç hastalarda olduğu görüldü. Hastalık şiddetinin artığı şiddetli Preeklampsi, Eklampsi ve hellp hastalarının daha erken haftalarda doğurduğu ve daha düşük doğum ağırlığına sahip olduğu saptandı.Hastaların perinatal sonuçları karşılaştırıldığında tıpkı fetal ağırlıkta olduğu gibi hastalık şiddeti artıkça intrauterin gelişme geriliği (IUGR) artığı satandı. Sadece gestasyonel hipertansif hastalarda fetal ağırlıktan farklı olarak hastaların \% 52'sinde IUGR tanısı aldığı saptandı. Aynı şekilde hastalık şiddetinin artığı gestasyonel hipertansif bozukluk gruplarında aşırı düşük doğum ağırlıklı (LBW) fetus ve 34 hafta altı doğum oranın artığı saptand1.

Sonuç: Üçüncü basamak sağlık kuruluşu olan hastanemizde gestasyonel hipertansif bozukluk insi dansının \% 6 oranında olduğunu bulundu. Çalışmamızda gestasyonel hipertansif bozukluk içinde preeklampsinin \% 69 oranında en sık görülen grup olduğu görüldü. Kronik hipertansiyonlu gebelerin ileri yaşlarda Eklamptik gebelerin daha genç yaşlarda olduğu izlendi. Hastalık şiddeti artıkça komorbidite (IUGR gibi) oranlarının artığı ve hastaların daha erken haftalarda doğurtuldu görüldü. Hastalık şiddeti artıkça erken doğum ve IUGR bağlı olarak çok düşük doğum ağırlıklı bebek oranın orantılı olarak artığı izlendi.

Anahtar kelimeler: Gestasyonel hipertansif bozukluk, Preeklampsi, perinatal sonuçlar

\section{Giriş}

Amerikan Kadın Doğum Uzmanları Koleji(ACOG) ve Birleşmiş Milletler Teşkilatı gebeliğe bağ l $_{1}$ hipertansifleri bozuklukları dört kategoriye ayırır. Bunlar, Kronik Hipertansiyon, Gestasyonel Hipertansiyon, Preeklampsi ve Eklampsidir. ${ }^{[1]}$ Preeklampsi gebelikte gebeliğin 20 . haftasından sonra tansiyon yüksekliği ( $\mathrm{TA}>140 / 90 \mathrm{~mm} \mathrm{Hg}$ ) ve proteinürinin( $>300 \mathrm{mg} /$ gün) birlikte olmasına denir. $\mathrm{Bu}$ klinik duruma nöbetlerinde eklenmesi durumuna da "Eklmapsi" denir. Gebelikte sadece tansiyon yüksekliği olmasına da Gestasyonel hipertansiyon denir. Eğer hastada tansiyon yüksekliği gebelikten ve 20 haftadan önce oluşursa buna da "kronik hipertansiyon" denir. Kronik hipertansiyon hastasına gebelikte proteinüri eşlik etmeye başlarsa "süperempoze preeklampsi” denir. Hipertansif hastada(bazen tansiyon yüksekliği olmadan da olur) karaciğ er enzim yüksekliği hemoliz ve trombosit düşüklüğü varsa bu durumda da hastaya "hellp" tanısı koyulur. Bunların hepsine Gebeliğin Hipertansif Bozuklukları(GHB) denir. Gebeliklerin yaklaşık \% 4-10'un GHB ile komplike olur. ${ }^{[2]}$ GHB anne yaşı $(16<$ ve35>), ailede GHB öyküsü, alkol kullanımı, kalp yetmezliği, inme sigara içme ve sol ventrikül hipertrofisi olan hastalarda daha sık görülür. ${ }^{[3]}$ GHB dünyadaki anne ölümlerinin en sık sebeplerinden olup ve yaklaşık \% 15 'inden sorumludur. ${ }^{[7]}$ Bu ölümlerin yaklaşı $\%$ 99'u gelişmekte olan ülkelerdedir. ${ }^{[2]}$ GHB perinatal ölümlerinde yaklaşık \% 25'inden sorumludur. ${ }^{[2]}$ Olumsuz perinatal sonuçlar hastalı̆̆ın şiddetine bağlıdır. Örneğin erken doğum riski normotasnif hastalarda \% 7,2 olarak en az, gestasyonel hipertansiyonda \% 12.5 ve preeklampsili(PE) hastalarda ise \% 39.2 olarak en yüksektir. ${ }^{[4]}$ Yapılan başka bir çalışmada PE hastalarda perinatal mortalite \% 13 iken eklampsili(E) hastalara ise \% 28 oranında görülür. ${ }^{[5]} \mathrm{GHB}$ hastaların yaşayan bebeklerinde uzun dönemde nöro-gelişimsel bozukluklarda daha sık görülür. ${ }^{[6]}$ GHB Perinatal morbidite ve mortalitenin nedeni plasenta yetmezliği ve buna bağlı olarak oligohidroamnioz, intrauterin gelişme geriliği, ablasyo plasenta ve prematürite ile ilişkili komplikasyonlardan kaynaklanır. ${ }^{[8]}$

Dünya üzerinde gelişmişlik düzeyine göre farklılık GHB hastalarının yönetimi prensip olarak aynı olsa da anne ölümlerinin gelişmemiş ülkelerdeki sıklığının fazlalığı yönetim ve bakım olanaklarının yetersizliğinden kaynaklanır. ${ }^{[9]}$

Ülkemizde PE ile maternal ve perinatal sonuçların karşılaştırıldığı birçok çalışma vardır. Çalışmamızda ACOG tanımladığı dört temel GHB'luğa Süperempoze preeklampsi ve Hellp ekledik ayrıca hastanın muayene ve laboratuar değerlerine göre de PE hastalarını da hafif ve şiddetli olarak ayırdık. Bu çalışmamızdaki amaç hastalığın şiddeti ve perinatal sonuçlarını karşılaştırmaktı.

\section{Yöntem}

Bu çalışmamızda 2010-2018 yılları arasında Mersin Üniversitesi Kadın Hastalıkları ve Doğum Kliniğinde GHB tanısı alan 451 hasta ve 122 tane de kontrol hastası 22/01/2020 tarih ve 2020/46 numaralı etik kurul onayı alınarak retrospektif olarak değerlendirildi. Hastalar hipertansif olarak tanılarına göre alt gruplara ayrıldı. Hastaların yaş doğum haftalarına göre ortalamaları alındı. GHB tanısı

2 I $\mathrm{P}$ a g e www.iiste.org 
alan hastalarda gebelik ile ilgili ek rahatsılıklar kaydedildi. Çoğul gebelikler listeye alınmadı, kontrol grubu 37 hafta üzerindeki maid gebelerden alındı. Çalışmada tüm gruplar kontrol grubu ile karşılaştırıldı. GHB gruplarından sadece Hafif Preeklmapsi ve Şiddetli Preeklampsi grubu kendi arasında karşılaştırıldı. Hasta verileri IBM SPSS 24 kullanılarak analiz edildi. İstatistiği olarak $\mathrm{p}<0,05$ olanlar anlamlı olarak değerlendirildi.

\section{Bulgular}

Çalışma süresi boyunca hastanemizde 7516 doğum gerçekleşti, bunların 451 (\% 6) GHB tanısı aldı. Katılımcıların ortalama yaşı $23 \pm 5$ idi. Ortalama sistolik kan basınç $150.9 \pm 13.7 \mathrm{mmHg}$, ortalama diyastolik kan basınç $101.6 \pm 6.2 \mathrm{mmHg}$ idi. Çalişmamızdaki GHB hastaların sıklı̆̆ Şekil 1'de gösterilmiştir. GHB hastalarının çoğunluğu şekilden de anlaşılacağı gibi PE (\%69) hastalardan oluşmaktadır.

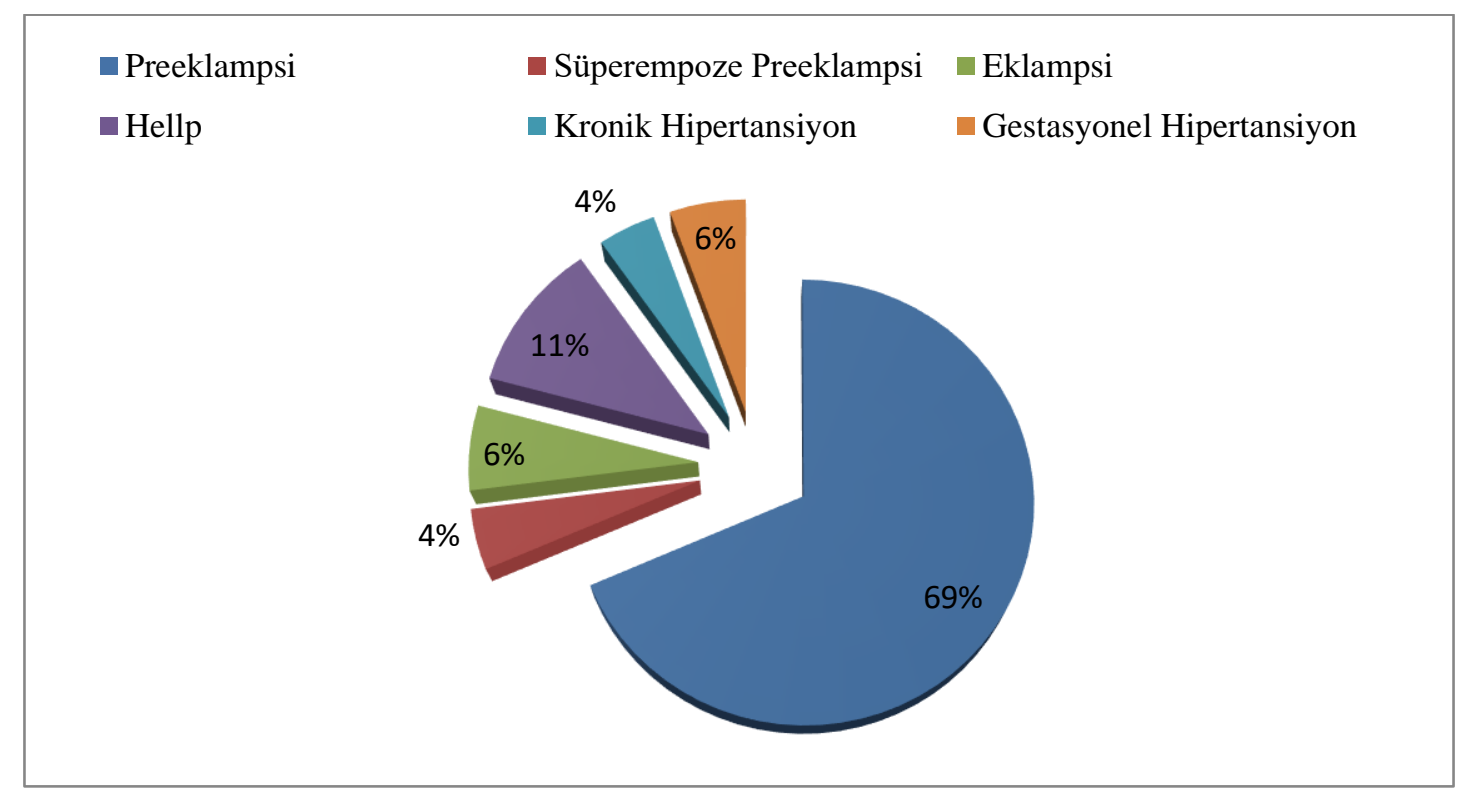

Hellp, hemoliz, karaciğer enzim yüksekliği ve trombositopeni

Şekil 1 Gestasyonel Hipertansif Bozuklukların Oranları

Hastaların demografik özellikleri incelendiğinde kronik hipertansiyon ve gestasyonel hipertansiyonlu annelerin daha ileri yaşlarda eklemapsinin ise daha genç hastalarda olduğu görüldü. Hastalık şidetinin artığı şiddetli PE, E ve hellp hastalarının daha erken haftalarda doğurduğu ve daha düşük doğum ağırlığına sahip olduğu saptandı(Tablo 1).

Tablo 1 GHB Hastaların Anne Yaşı, Fetal Ağırlık ve Gebelik Haftası ortalamaları

\begin{tabular}{|c|c|c|c|c|c|c|c|c|}
\hline & $\begin{array}{c}\text { Hafif PE } \\
(n=190) \\
\text { Ort } \pm \text { SD }\end{array}$ & \begin{tabular}{|c|} 
Şiddetli PE \\
$(\mathbf{n}=\mathbf{1 1 9})$ \\
Ort \pm SD
\end{tabular} & \begin{tabular}{|c|} 
Süperempoze \\
Preeklampsi \\
$(n=20)$ \\
Ort \pm SD
\end{tabular} & $\begin{array}{c}E \\
(n=28) \\
\text { Ort } \pm S D\end{array}$ & $\begin{array}{c}\text { Hellp } \\
(n=50) \\
\text { Ort } \pm \text { SD }\end{array}$ & $\begin{array}{c}\text { Kronik } \\
\text { hipertansiyon } \\
(n=19) \\
\text { Ort } \pm \text { SD }\end{array}$ & $\begin{array}{c}\text { Gestasyonel } \\
\text { hipertansiyon } \\
(\mathbf{n}=\mathbf{2 5}) \\
\text { Ort } \pm \text { SD }\end{array}$ & $\begin{array}{l}\text { Kontrol } \\
(n=122) \\
\text { Ort } \pm \text { SD }\end{array}$ \\
\hline Anne yaşı(yıl) & $31,1 \pm 6,1$ & $30,5 \pm 6^{\mathrm{a}}$ & $33,1 \pm 5,6^{b}$ & $26,0 \pm 6,2^{c}$ & $31,2 \pm 7,5$ & $37,6 \pm 5,4^{d}$ & $34,7 \pm 5,3^{\mathrm{d}}$ & $29,9 \pm 5,8^{\mathrm{a}, \mathrm{b}, \mathrm{c}, \mathrm{d}}$ \\
\hline $\begin{array}{l}\text { Bebek } \\
\text { A ğırlığı(gram) }\end{array}$ & $2352 \pm 886^{\mathrm{c}}$ & $1897 \pm 857^{\mathrm{e}}$ & $2563 \pm 1183^{\mathrm{e}}$ & $1840 \pm 664^{\mathrm{e}}$ & $1772 \pm 731^{\mathrm{e}}$ & $3217 \pm 943^{\mathrm{e}}$ & $2892 \pm 760^{\mathrm{e}}$ & $3318 \pm 440^{\mathrm{c}, \mathrm{e}}$ \\
\hline $\begin{array}{l}\text { Doğum } \\
\text { Haftası }\end{array}$ & $35,0 \pm 3,3^{\mathrm{e}}$ & $33,3 \pm 3,6^{\mathrm{e}}$ & $34,5 \pm 4,7^{\mathrm{e}}$ & $33,2 \pm 3,4^{\mathrm{e}}$ & $33,0 \pm 3,8^{\mathrm{e}}$ & $36,5 \pm 3,0^{\mathrm{e}}$ & $36,9 \pm 2,1^{\mathrm{e}}$ & $38,6 \pm 0,8^{\mathrm{e}}$ \\
\hline
\end{tabular}

${ }^{\mathrm{a}}=0,003,{ }^{\mathrm{b}}=0,02,{ }^{\mathrm{c}}=0,002,{ }^{\mathrm{d}}=0,001,{ }^{\mathrm{e}}=0,0001$ sonuçları $\mathrm{p}<0,05$ olduğundan anlamlı bulunmuştur. 
Hastaların perinatal sonuçları karşılaştırıldığında tıpkı fetal ağırlıkta olduğu gibi hastalık şiddeti artıkça intrauterin gelişme geriliği(IUGR) artığı satandı. Sadece gestasyonel hipertansif hastalarda fetal ağırlıktan farklı olarak hastaların \% 52'sinde IUGR tanısı aldığı saptandı. Aynı şekilde hastalık şiddetinin artığı GHB gruplarında aşırı düşük doğum ağırlıklı (LBW) fetus ve 34 hafta altı doğum oranın artı̆̆ saptandi(Tablo 2).

Tablo 2 GHB Hastalarının Perinatal Sonuçları

\begin{tabular}{|c|c|c|c|c|c|c|c|c|}
\hline & $\begin{array}{c}\text { Hafif PE } \\
\text { n(\%) }\end{array}$ & $\begin{array}{c}\text { Şiddetli PE } \\
\mathbf{n}(\%)\end{array}$ & \begin{tabular}{|} 
Süperempoze \\
Preeklampsi \\
$\mathbf{n}(\%)$
\end{tabular} & $\begin{array}{c}\mathbf{E} \\
\mathbf{n}(\%)\end{array}$ & $\begin{array}{l}\text { Hellp } \\
\text { n(\%) }\end{array}$ & $\begin{array}{c}\text { Kronik } \\
\text { hipertansiyon } \\
\mathbf{n}(\%)\end{array}$ & $\begin{array}{c}\text { Gestasyonel } \\
\text { hipertansiyon } \\
\mathbf{n}(\%)\end{array}$ & $\begin{array}{c}\text { Kontrol } \\
\mathbf{n}(\%)\end{array}$ \\
\hline Oligohidramnios & $20(10,6)^{a, b}$ & $23(19,5)^{a, b}$ & $2(10)^{b}$ & $2(7,1)^{\mathrm{c}}$ & $6(12,5)^{\mathrm{b}}$ & $3(15,8)^{b}$ & $5(20)^{b}$ & $0(0)^{b, c}$ \\
\hline IUGR & $83(43,7)^{\mathrm{b}}$ & $58(48,7)^{\mathrm{b}}$ & $6(30,0)^{b}$ & $15(53,6)^{b}$ & $27(54,0)^{\mathrm{b}}$ & $4(21,1)^{b}$ & $13(52,0)^{b}$ & $0(0,0)^{\mathrm{b}}$ \\
\hline IUMF & $1(0,5)$ & $3(2,5)$ & $0(0,0)$ & $2(7,1)^{c}$ & $4(8,0)^{c}$ & $0(0,0)$ & $0(0,0)$ & $0(0,0)^{\mathrm{c}}$ \\
\hline $\begin{array}{l}\text { Düşük doğum } \\
\text { ağırlığı } \\
\text { (Fetal } \\
\text { ağırlık<2500) }\end{array}$ & $108(56,8)^{b, d}$ & $87(73,1)^{\mathrm{b}, \mathrm{d}}$ & $8(40)^{\mathrm{b}}$ & $23(82,2)^{b}$ & $40(81,6)^{b}$ & $2(10,5)^{b}$ & $7(28)^{b}$ & $0(0,0)^{\mathrm{b}}$ \\
\hline $\begin{array}{l}\text { Aşırı düşük doğum } \\
\text { ağırlığı(fetal } \\
\text { ağırlık<1500) }\end{array}$ & $38(20,0)^{b, d}$ & $44(37,0)^{\mathrm{b}, \mathrm{d}}$ & $4(20,0)^{\mathrm{b}}$ & $8(28,6)^{b}$ & $18(36,7)^{b}$ & $1(5,3)^{\mathrm{b}}$ & $1(4,0)^{\mathrm{b}}$ & $0(0,0)^{b}$ \\
\hline Cinsiyet $\quad \mathrm{K} \mathbf{}$ & $92(48,4)$ & $55(46,2)$ & $12(60,0)$ & $12(42,9)$ & $28(58,3)$ & $9(47,4)$ & $11(44,0)$ & $62(50,8)$ \\
\hline Erkek & $98(51,6)$ & $64(53,8)$ & $8(40,0)$ & $16(57,1)$ & $20(41,7)$ & $10(52,6)$ & $14(56,0)$ & $60(49,2)$ \\
\hline $\begin{array}{l}\text { Preterm doğum } \\
\text { (doğum haftası }<34 \\
\text { hafta) }\end{array}$ & $58(30,5)^{b, d}$ & $61(51,3)^{b, d}$ & $6(30,0)^{\mathrm{b}}$ & $15(53,6)^{b}$ & $29(58,0)^{\mathrm{b}}$ & $4(21,1)^{b}$ & $2(8,0)^{b}$ & $0(0,0)^{\mathrm{b}}$ \\
\hline
\end{tabular}

${ }^{\mathrm{a}}=0,02,{ }^{\mathrm{b}}=0,0001,{ }^{\mathrm{c}}=0,003, \stackrel{\mathrm{d}=}{=}=0,001$, sonuçları $\mathrm{p}<0,05$ olduğundan anlamlı bulunmuştur.

\section{Tartıșma}

ACOG, gebeliklerin\% 4-6'sının hipertansif bozukluklarla komplike olduğunu belirtmiştir. GHB gelişmekte olan ülkelerde kanamadan sonra anne ölümlerinin en sık sebeplerindendir. ${ }^{[10]}$ GHB prevalansı dünyanın farklı yerlerinde farklı sıklıklarda izlenebilir. Yüksek prevalans için çeşitli nedenlere bağlanmıştır. Bunlar PE ve E konusunda eğitim eksikliği, tıbbi yardıma ilişkin kaynak eksikliği, nem, sıcaklık, farkındalık ve batıl inançlar. ${ }^{[11,12]}$ GHB tanısında gecikmeler olmadığında anne ölümleri önlenebilir. ${ }^{[13]} \mathrm{PE}$ ve E gelişmekte olan ülkelerde anne ve bebek mortalite ve morbiditesin başlıca nedenleridir. ${ }^{[14]}$

GHB sadece anne sağlığını değil aynı zamanda fetal sağlığı da etkilemektedir. Özellikle gebeliğin 32 . haftasından önce PE gelişen hastalarda maternal ve fetal komplikasyon daha izlenir. Xiong ve arkadaşlarının yaptığı bir çalışmada preeklampsinin yeni doğan en sık komplikasyonunu erken doğuma bağlı LBW olarak tarif etmişlerdir. ${ }^{[15]}$ Günümüzde prematüritenin dolayısı ile LBW en sık sebebi GHB bağlı olarak iatrojenik olarak hastanın erken doğurtulmasıdır. ${ }^{[16]}$ Bizim çalışmamızda da görüldüğü gibi GHB olan hastalar kontrol grubuna göre daha erken haftalarda doğurmakta veya doğurtulmakta buna bağlı olarak GHB doğan bebekler daha düşük doğum ağılıklı olduğu saptandı. Bunun yanında çalışmamızda hastalık şiddetinin artığı gruplarda morbidite oranlarının da orantılı olarak artığı saptandı. $\mathrm{Bu}$ sonuçlar daha önce yapılan çalışmalar ile uyumluydu. ${ }^{[17]}$

GHB hastalarında uteroplasental perfüzyon bozulduğu olduğundan bebekler haftalarına göre küçük(IUGR) olduğundan buda LBW bir diğer nedenidir. Buda tıpkı erken doğum haftasındaki korelasyondaki gibi hastalık şiddeti artıkça IUGR hastalarında artı̧̧ göstermekledir.

Herkesin bildiği gibi GHB oluşma nedenlerinden biri de plasentanın uterusa yeterice invaze olamamasıdır. Bu invazyon yetersiz olduğundan fetus yeterince kanlanamamakta bunun sonucunda fetus yeterince idrar çıkaramadığından, GHB annelerin bebeklerinde oligohidroamnioz daha sık görülür. Dikkat edilecek olursa GHB şiddeti artıkça IUGR ve oligohidroamnioz birlikte korele bir şekilde artmaktadır. Bu daha önce Chamberlain ve arkadaşlarının yaptı̆̆ı çalışmada oligohidroamnioz, IUGR ve hipertansiyonun $\% 40$ oranında eşlik etmesi ile uyumlu çıkmıştır. ${ }^{[18]}$ Bizim çalışmamızda da GHB olan hastalar da oligohidroamnioz ve IUGR oranları anlamlı olarak fazla izlendi.

Ayrıca çalışmamızda bebek cinsiyeti ve GHB grupları ve kontrol hastaları arasında farklılık saptanmadı. Çalışmamız GHB gruplara ayrılması açısından özgün bir çalışma olmasına rağmen bazı konularda yetersiz oldu. Grupların ortalama ve yüzdelik değerleri biri birinden farklı görünmesine rağmen PE grubu 
hariç gruplarını anlamlılık düzeyine bakamadık. İkinci tek merkezli bir çalışma olduğundan sonuçları genelleyemeyiz.

\section{Sonuç}

Üçüncü basamak sağlık kuruluşu olan hastanemizde GHB insidansının \% 6 oranında olduğunu saptadık. Çalışmamızda GHB içinde preeklampsinin \% 69 oranında en sık görülen grup olduğu görüldü. Kronik hipertansiyonlu gebelerin ileri yaşlarda E gebelerin daha genç yaşlarda olduğu izlendi. Hastalık şiddeti artıkça ko morbidite (IUGR gibi) oranlarının artığı ve hastaların daha erken haftalarda doğurtuldu görüldü. Hastalık şiddeti artıkça erken doğum ve IUGR bağlı olarak çok düşük doğum ağırlıklı bebek oranın orantılı olarak artığ 1 izlendi.

$\mathrm{Bu}$ çalışmamızda GHB grubundaki hastaların şiddeti artıkça perinatal sonuçlarında o oranda artığını ve hastalık şiddeti artıkça LBW ve IUGR oranının artığını bunların bir biri ile ve hipertansiyonun şiddeti ile ilişkili olduğunu saptand.

\section{Kaynaklar}

[1] Schroeder BM, American College of Obstetricians and Gynecologists: ACOG practice bulletin on diagnosing and managing preeclampsia and eclampsia. Am Fam Physician. 2002;66: 330-331.

[2] Goldenberg RL, McClure EM, Macguire ER, Kamath BD, Jobe AH. Lessons for low-income regions following the reduction in hypertension-related maternal mortality in high-income countries. Int J GynaecolObstet. 2011;113(2):91-5.

[3] Leeners B, Rath W, Kuse S, Irawan C, Imthurn B, Neumaier-Wagner P: BMI: new aspects of a classical risk factor for hypertensive disorders in pregnancy. Clin Sci (Lond). 2006, 111: 81-86.

[4] Shen M, Smith GN, Rodger M, White RR, Walker MC, Wen SW: Comparison of risk factors and outcomes of gestational hypertension and pre-eclampsia. PLoS One. 2017, 12: 0175914.

[5] Zupan J. Perinatal mortality in developing countries. N Engl J Med. 2005; 352(20):2047-8.

[6] Duley L. The global impact of pre-eclampsia and eclampsia. Semin Perinatol. 2009;33: 130-7.

[7] Zhang WH, Alexander S, Bouvier-Colle MH, Macfarlane A, MOMS-B Group: Incidence of severe pre-eclampsia, postpartum haemorrhage and sepsis as a surrogate marker for severe maternal morbidity in a European population-based study: the MOMS-B survey. BJOG. 2005,112:89-96.

[8] American College of Obstetricians and Gynecologists (ACOG). Practice bulletin No.33: Diagnosis and management of preeclampsia and eclampsia. Obstet Gynecol. 2002;99: 159-67.

[9] Danso KA, Opare-Addo HS. Challenges associated with hypertensive disease during pregnancy in lowincome countries. Int J Gynaecol Obstet. 2010; 110(1):78-81. Epub 2010/04/07. S00207292(10)00103-7

[10] Shah N, Khan NH: Socio-demographic characteristics and the three delays of maternal mortality. Rawal Med J. 2009, 19(2)95-8

[11] Hasan IJ, Nisar N: Women's perceptions regarding obstetric complications and care in a poor fishing community in Karachi. J Pak Med Assoc. 2002, 52: 148-152.

[12] Taşın C, Bektaş K. Seasonal change of the prevalence of hypertensive disorders of pregnancy. Perinatal Journal. 2019;27(2):101-104.

[13] Koenig MA, Jamil K, Streatfield PK, et al.: Maternal health and care-seeking behavior in Bangladesh: findings from a national survey. Int Fam Plan Perspect. 2007, 33: 75-82. Doi: $10.1363 / 3307507$ 
[14] Vanderjagt DJ, Patel RJ, El-Nafaty AU, Melah GS, Crossey MJ, Glew RH: High-density lipoprotein and homocysteine levels correlate inversely in preeclamptic women in northern Nigeria. Acta Obstet Gynecol Scand. 2004, 83: 536-542.

[15] Xiong X, Demianczuk NN, Saunders LD, Wang FL, Fraser WD: Impact of preeclampsia and gestational hypertension on birth weight by gestational age. Am J Epidemiol. 2002, 155:203-209.

[16] Halimi Asl AA, Safari S, Parvareshi Hamrah M: Epidemiology and related risk factors of preterm labor as an obstetrics emergency. Emerg (Tehran). 2017, 5:e3.

[17] Tranquilli AL, Dekker G, Magee L, et al. The classication, diagnosis and management of the hypertensive disorders of pregnancy: A revised statement from the ISSHP. Prednancy Hypertens. 2014;4(2):97-104.

[18] Chamberlain PF, Manning FA, Morrison I, et al. Ultrasound evaluation of amniotic fluid volume. I. The relationship of marginal and decreased amniotic fluid volumes to perinatal outcome. Am J Obstet Gynecol. 1984;150:245. 